TABLE III. $\rightarrow$ Opendtoms for Remaval of Fotris from Abdominal Cavity by

\begin{tabular}{|c|c|c|c|c|c|c|c|c|c|}
\hline No. & Date. & Operator and Locality. & $\begin{array}{l}\text { Hospital or } \\
\text { Private house }\end{array}$ & Age & $\begin{array}{c}\text { Previous } \\
\text { confinements. }\end{array}$ & $\begin{array}{l}\text { Time of operation } \\
\text { after ruptute }\end{array}$ & Condition of woman. & Result to woman. & $\begin{array}{l}\text { Result to } \\
\text { child. }\end{array}$ \\
\hline 7 & $\begin{array}{c}18 s 3 \text {. } \\
\text { Dec. is }\end{array}$ & Dr. Luigi Violani, Forli, Italy & Private house & 27 & 3 & i2 hours & In state of collapse & Died in 48 hours. & $\begin{array}{l}\text { Dead before } \\
\text { operation. }\end{array}$ \\
\hline
\end{tabular}

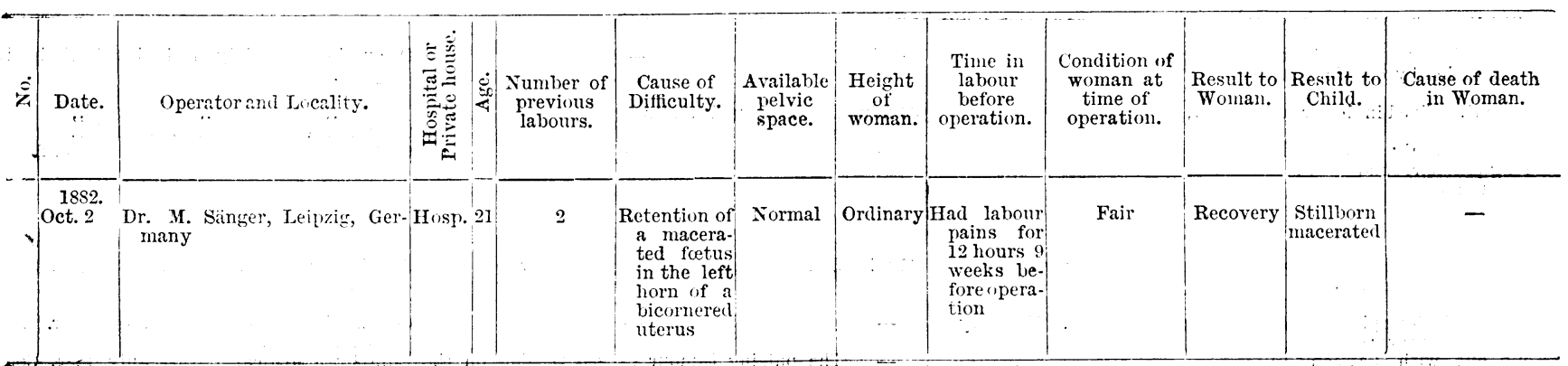

\section{A CASE OF PORRO'S OPERATION.}

Read before the West Kent District, of the South-Easterit Branch.

\section{BY. FANCOURT BARNES, M.D.}

Obstetric Physician to the Great Northern Hospital; Physician to the British Lying-in Hospital and the Chelsea Hospital for Women.

THE case which I am about to relate is, as far as I know, the sixth in which Porro's operation. has been resarted to in this country. The patient, Mrs. S., aged 28 , primipara, was sent into the British Lyingin Hospital, on September 10th, 18s4, by Dr. Pearce, on account of a pelvic tumour obstructing labour: I was sent for to the hospital at 9.30 P.Mr., and, on making a vaginal examination, found the pelvis nearly completely occupied by a hard semi-solid tumour, lying behind the posterior wall of the vagina, and fixed to the sacrum. The os uteri was only dilated to the size of a five-shilling piece, althongh the patient had been forty-eight hours in labour, and said that the liquor amnii had escaped soon after the commencement of labour. Finding that it would be impossible, owing to the narrow space between the tumour and pubes, to deliver by craniotomy without the certainty of rupturing the tumour, I endeavoured to push the tumour up out of the pelvis. - This, however, $I$ was unable to to, it being firmly fixed to the concavity of the sacrum. It being now clear that one or other of the Crsarean operations would be necessary, I sent for my colleagues, Drs. Phillips and Handfield-Jones, and my father, Dr. R. Barnes. On their arrival, the patient was examined by them, and further unsuccessful attempts made to push the tumour up out of the pelvis. After consultation, it was decided to deliver by abdominal section, in the interest of the mother as well as of the child. The patient having been anæsthetised by Dr. Phillips, I procoeded, at $12.30 \mathrm{~A}$ M., to the operation. An incision from one inch below the umbilicus to an inch above the pubes was made through the abdominal wall. I then made an incision about four inches in length perpendicularly, down the anterior wall of the uterus. The right shoulder of the child presented at the uterine opening. I therefore passed $m y$ hand into the uterus, seized a foot, and delivered a live male child, weighing $7 \mathrm{lbs}$. Having separated the child from the cord, I removed the placenta. The hæmorrhage from the ineised uterine walls was controlled by Sydney Jones's ovariotomy clamp-forceps. The uterus, which was now empty and contracted, was drawn forwards out of the abdomen. A Koberlé's scrre-noend was then anplied round the cervix, underneath the ovaries. The serre-naud was tightened, and the uterus, together with the ovaries, amputated just above the serre-noud. The pedicle formed by the cervix was transfixed by two straight pins, and fixed outside the abdomen at the lower end of the incision. Some sponges, on sticks, were passed down into the pelvis, and returned unstained, showing that no fluid or blood had escaped into the peritoneum. The abdominal incision was united by silver-sutures. The wound was covered over with cotton-wool ; a piece of carbolised lint being placed over the stump. With the exception of the spray, the operation was performed under antiseptic precautions. The operation occupied forty minutes. The child survived.

During the night, the patient slept at intervals, and was free from pain. She received four doses of thirty minims of tincture of opium during the night.

On September 11 th, at 10 A.M., nine ounces of urine was drawn off. Her pulse was 84 , temperature $98.2^{\circ} \mathrm{Fahr}$. The serre-noud was tightened, and some perchloride of iron was applied to some oozing vessels in the stump. I prescribed compound spirit of chloroform, fluid extract of ergot, and tincture of digitalis, to be taken every four hours. Between twelve and one o'clock, she vomited about two ounces of yellow mucus. She had iced champagne at intervals of twenty minutes during the afternoon, to allay the vomiting. The urine was drawn at 8.30 P.M. At 10 P.M., the pulse was 104 ; temperature $98.2^{\circ}$.

At 10 A.M. on September 12th, the pulse was 96 , and the temperature 99. $4^{\circ}$. Eighteen ounces of urine had been drawn off during the night. The abdominal wound, which looked healthy, and had united, was dressed under the carbolic spray. The pedicle was healthy and odourless. Tongue moist and clean. The voriititing had ceased. Nine ounces of urine were drawn off. At 3.30 P.M., the serre-noud was tightened, and nine ounces of urine were drawn off. She was taking beef-tea, gruel, milk and soda-water, alternately, in doses of a tablespoonful. At 10.30 P.M.; the tongue was clean and moist; pulse 96 , temperature $99.8^{\circ}$. The respirations had gone up to $21^{\text {. }}$ She looked well, and said she felt comfortable.

September 13 th, 10 A.Mr. The pulse was 120 ; respirations 21 ; temperature $10.2 .8^{\circ}$. She had had a rigor at $6.45 \mathrm{~A} . \mathrm{M}$. The urine was drawn three times during the night; eight ounces each time. The vagina was syringed with carbolic solution, and some offensive sanious fluid washed out. The stump looked healthy. She was ordered quinine in ten-grain doses, with tincture of opium. At 3.30 in the afternoon, six ounces of urine were drawn off. Nourishment was well taken, but the abdomen had become distended and tympanitic. Pulse 120, respirations 20 . In the evening, at 10 P.M., the pulse was 122 ; temperature $100.4^{\circ}$; respiration 24 . During the day, three enemata of soap and water, with turpentine and oil, were administered, which gave vent to large quantities of flatus, and relieved the abdominal distension. The serre-nceud was tightened, and the pedicle found healthy and free from smell. The vagina was syringed with carbolic lotion, which returned clear.

September 14 th, 10 A.M. The pulse was 120 ; respiration 28 ; temperature $101^{\circ}$. Nine ounces of urine had been drawn off at 4 P.M. She had hiccough. She was perspiring freely. She had passed some urine into the bed. At 3.30 in the afternoon, the pulse was 140 . Diarrhœa had set in, with clay-coloured stools. In the evening, she became delirious, and tried to get out of bed. During the night, she rapidly grew worse, and died at $4.45 \mathrm{~A}$. M. on September 15 th.

The post mortem examination was made by Dr. R. Burnet, twelve hours after death. The body was that of a large, well developed, and well nourished woman, aged 28. A complete examination was forbidden ; hence only the pelvis and abdominal, cavity, through the incision, could be examined. The whole of the incision had united, except the lower 
Laparotomy, followed by Amputation of Ruptured Uterus, with Ovaries.

\begin{tabular}{|c|c|c|c|c|}
\hline $\begin{array}{l}\text { Cause of death in } \\
\text { woman. }\end{array}$ & Treatment of pedicle. & Dressing, ordinary or Listerian. & Duration of operation. & Reference. \\
\hline Septic peritonitis & $\begin{array}{c}\text { Extraperitoneal ; Cintrat's } \\
\text { serre-nceud }\end{array}$ & Inperfect Listerian & 40 minutes & Raccoglitore Medico di Forli, 1Ss3, vol. xx, p. (is4. \\
\hline
\end{tabular}

Table I, for reasons assigned.

\begin{tabular}{|c|c|c|c|c|}
\hline Treatment of pelicle. & Dressing, ordinary or Listerian. & 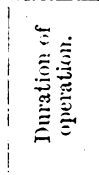 & Special Notes. & Reference. \\
\hline $\begin{array}{l}\text { Peritoneum stitched over stump } \\
\text { with s silk sutures; peclicle } \\
\text { (ropped in constricted with } \\
\text { elastic ligature }\end{array}$ & Listerian, without spraj & 1: hours & $\begin{array}{l}\text { Operation performed a weeks after death of } \\
\text { fotus, when separation of a decidua oc- } \\
\text { curred, with symptoms of internial hitmor- } \\
\text { rhage and peritonitis }\end{array}$ & $\begin{array}{l}\text { Centralblatt für Gynakologie, 1SS2. Com- } \\
\text { munication direct from operator }\end{array}$ \\
\hline
\end{tabular}

part, where the stump of the uterus was found transfixed by the needles, and commenced to scparate. The surfaces of the incision were healthy; and, when the stitches were removed, the adhesion had to be broken down. The abdominal cavity appeared healthy; there was no fluid, and no signs of peritonitis. On passing the hand into the pelvis, a large tumour could be felt, lying rather towards the left side, and about as large as a child's head, tense, and globular in form. When raised, the tumour was found to be attached to the posterior aspect of the pelvic margin by a peduncle narrow at the tumour, and spreading out on the sacrum in a digitate manner.

On removing the tuinour, it was found to be a large globular semisolid mass, with several definite thickenings in its walls, apparently cystic. On opening the cyst, it was found to contain a quantity of thick creamy sebaceous matter; a mass of hair about half an inch thick, and about the size of a penny in circumference. This mass of hair was not attached to the wall, but slid freely on a fibrous band which penetrated it. On dissection, the nodular masses in the wall were found to contain several more or less completely developed teeth.

Remarks. - Neither the operation of Porro nor the ordinary Cæsarean section is likely ever to be frequently resorted to in England, for the simple reason that, in our country, badly distorted pelves are not commonly met with. In Italy and Germany, the various deformities of the pelvis arising from rickets and osteomalacia-an Italian name, by the way, for an almost Italian disease-are abundant. Spiegelberg, indeed, thought that, in Germany, nearly every seventh pelvis might be regarded as deformed. It is of absolute necessity to a just appreciation of the advantages and disadvantages of Porro's operation by the profession in this country, that the failures should be scrupulously published. We know that the successful cases will not be concealed. On referring to the table drawn up by Dr. Godson, I find that, out of five cases of Porro's operation in Great Britain which he has collected, only two had been published: the first by Professor Simpson; in which the patient died; the second by Dr. Godson himself, in which the patient recovered. The remaining three deaths remain unpublished. And so, until Dr. Godson collected all the cases he could, the death-rate in Porro's operation in this country, gauged by published cases, might have erroneously been set down at only 1 in 2 , whereas it has really been 5 in 6 . I have mentioned this to emphasise the importance of all such cases being published. Out of the 138 operations collected by Dr. Godson, 77 deaths are recorded, against 61 rocoveries. It must, therefore, at present, be regarded as a most severe proceeding.

In the case I have just related I was obliged to resort to Porro's operation, owing to the impossibility of delivering the child per vias naturales. The pelvis was occupied by a fired semi-solid tumour, leaving only room for the examining finger to pass between it and the pubes to the os uteri at the brim. In performing the operation, I incised the uterus whilst it was still in the abdominal cavity; I then removed both the child and the placenta before drawing the uterus forwards out of the pelvis. Ny reason for emptying the uterus of the placenta as well as of the child before applying the serre-noend is that it allows of more perfect and natural contraction of the uterus, and thus materially facilitates the adjustment of the scrre-nezed round the uterine neck. It further allows the cervix to be embraced by a smaller loop of wire, and so obviates the tightening of the wire too soon after its application. Müller's modification of making a large abclominal incision and then drawing out the gravid uterus before incising it, seems to me a needless and dangerous complication. The object is to prevent hæmorrhage by applying a constrictor round the cervix before incising the uterus, and also to prevent blood and am. niotic fluid escaping into the peritoneum. Both these accidents are easily avoided by an assistant supporting the uterus while it is being incised, and by applying pressure by clamps or the hand to the walls of the uterus, until it is drawn out of the abdomen. In my case, no blood or fluid ran into the abdominal cavity. Where it is considered advisable to insert a drainage-tube, I think it would be best to pass it through a small opening in the posterior vaginal pouch into the peritoneum.

The two chief dangers of the operation are, first, shock; second, blood-poisoning. It is well known that amputation through the cervix uteri is a great shock to the nervous system. Dr. Savage regards this as the chief danger in cases of hysterectomy for fibroid tumours. If the patient, however, rally from the shock, as in my case, there is still the probability of septicæmia to be encountered. Up to the fourth day my patient did not exhibit any bad symptom, and seemed to be progressing so well that her recovery seemed assured. The prevention of septicæmia must always be difficult where we have to deal with a pedicle fixed outside the abdomen. I regard this as the chief danger after the operation, and cannot help thinking that, as in ovariotomy, it would be safer to transfix the pedicle, securely tie it, drop it into the abdomen, and close up the wound, leaving, if necessary, a drainage-tube through the vaginal wall into the peritoneum. In the case I have described, the presence in the pelvis of a suppurating dermoid cyst was an additional and great source of septic danger. I think that, had it not been for this complication, the patient would have recovered.

In the British MEIICAL Journal, November 1st, 1884, a case is reported from the Prince Alfred Hospital, Sydney, in which Dr. Goode removed both ovaries, together with the nterus, which was amputated through the cervix uteri. Instead of fixing the pedicle as usual in the lower angle of the abdominal wound, Dr. Goode transfixed it with a double ligature of carbolised silk, tied it, and returned it into the abdomen. The patient recovered.

The results of the treatment of the pedicle by the intraperitoneal method have not hitherto been more encouraging than those obtained by the usual method of securing it in the abdominal wound. It is reassuring, however, to find that, of the deaths after the intraperitoneal treatment of the pedicle, not one is attributed to blceding from the pedicle. Seeing that the dangers from septic absorption are in. creased by the extraperitoneal method, this should be an argument in favour of a further trial of the intraperitoneal treatment of the pedicle.

To conclude; we are yet far off the day when it will be possible to decide which of the three, Porro's operation, Casarean section, or laparo-elytrotomy, affords the safest chance for the mother. 